\title{
THE
}

\section{Panel Discussion on Libraries and Best Practices in Fair Use}

Andrée J. Rathemacher

University of Rhode Island, andree@uri.edu

Follow this and additional works at: https://digitalcommons.uri.edu/lib_ts_pubs

Part of the Intellectual Property Law Commons, and the Library and Information Science Commons

\section{Citation/Publisher Attribution}

Rathemacher, Andrée J.. "Panel Discussion on Libraries and Best Practices in Fair Use." , (2012). doi: 10.1080/1941126X.2012.706139.

This Article is brought to you for free and open access by the Technical Services at DigitalCommons@URI. It has been accepted for inclusion in Technical Services Department Faculty Publications by an authorized administrator of DigitalCommons@URI. For more information, please contact digitalcommons-group@uri.edu. 


\title{
Panel Discussion on Libraries and Best Practices in Fair Use
}

Andrée J. Rathemacher

\begin{abstract}
This report covers a panel discussion on the Code of Best Practices in Fair Use for Academic and Research Libraries, published in January 2012 by the Association of Research Libraries (ARL) [1]. The panel was held at the Massachusetts Institute of Technology (MIT) on March 23, 2012 and was hosted by the MIT Libraries. Panelists were Patricia Aufderheide of the Center for Social Media at American University, Brandon Butler of ARL, Kyle Courtney of Harvard Law School, and Jay Wilcoxson of MIT.
\end{abstract}

\section{Fair Use and Research Librarians}

The panelists were introduced by MIT librarians Diane Geraci, Associate Director for Information Services, and Ellen Duranceau, Program Manager, Scholarly Publishing and Licensing, who explained that the co-facilitators of the Code are in the process of speaking to librarians around the country to discuss how its principles can help solve local challenges and improve policies dealing with copyright and fair use. Patricia Aufderheide spoke first. Aufderheide is University Professor in the School of Communication at American University and founder of the Center for Social Media there. She heads the Fair Use and Free Speech research project at the Center and is the co-author, with Peter Jaszi, of the book Reclaiming Fair Use: How to Put Balance Back in Copyright, published last year. 
Aufderheide explained that creating codes of best practice for fair use [2] is important because judges take into account the common practices of a given community when deciding fair use cases. If embraced by the academic library community, the Code of Best Practices in Fair Use for Academic and Research Libraries will help provide a solid legal foundation for many current library practices and give librarians more confidence in exercising their fair use rights.

Aufderheide clarified that the purpose of copyright law as written and understood by legal scholars and judges is not to protect content creators (that is just a tactic), but to promote the creation of culture. Copyright law does this by rewarding creators with a limited monopoly while also encouraging new uses of existing culture. This balance is essential. Culture is the currency of a civilization, and all new culture references existing culture. If culture is locked up such that existing copyright owners become private censors, then creators can only make new culture that others let them make. Culture is social, collective, and collaborative, and it is the principle of fair use - the legal, unauthorized use of copyrighted material under some circumstances—that balances the interests of copyright owners and creators of new culture. If society allowed existing copyright holders to privately censor uses of their work in perpetuity, this would violate the First Amendment of the U.S. Constitution. The exceptions and limitations of copyright as embodied in fair use are a core feature of copyright law, not a special favor.

Brandon Butler, Director of Public Policy Initiatives at ARL, added that fair use is flexible. This flexibility opens up space for creativity not just by creators, but also by lawyers and judges. Fair 
use is neither black-and-white nor quantifiable. It is a space where a smart lawyer confronting a new situation can apply new ways of thinking. For over a century, fair use was not part of the written copyright law. The concept of fair use was created in the 1840 s by a judge exercising his common law power to not enforce the law when it seemed unfair. Only in the 1976 revision of copyright law was fair use put into writing, and even then Congress made it explicit that judges would continue to have a wide degree of latitude in their interpretations of fair use.

When ruling on a fair use case, judges consider four factors. The first factor is the reason for the use: Is someone simply trying to profit unfairly from another person's work, or are they doing something new and different? Second, what kind of work was used? Butler explained that this factor has been the home of some bad doctrines. It used to be the case that if a creator wanted to make use of someone else's work and that work was not published, judges believed that the creator could not use it, as they mistakenly believed that the original author had the absolute right to decide when his or her work would be published. This notion was ultimately rejected, and now the fact that something is unpublished does not bar it from being used under fair use. A third factor for consideration is the amount of the original work used. It was formerly the case that if a creator made use of an entire work by someone else, the use was not considered fair. This interpretation, too, has been discarded over the last few decades; current interpretations of fair use law are more nuanced and consider whether the amount used was appropriate. The fourth factor is effect on the market. Here, too, interpretations have evolved. This factor used to be the most important: whether or not the use in question damaged the market for the original work. However, just because copyright holders can be paid when their work is used by others 
does not mean that they should be paid. A more important question is whether the use in question has an effect on the legitimate market for the original work.

Butler explained that judges in recent years have given more weight to the balancing features of fair use, as copyright laws have become more restrictive, with automatic protection for all creative works, longer terms, and increased awards for damages. The Supreme Court has ruled that fair use is covered by First Amendment protections of free speech; if it were not for the right of fair use, copyright would be an unconstitutional regime because it would allow private censorship by copyright holders. When the Supreme Court in the recent Golan v. Holder case restored copyright status to foreign works previously in the public domain, the justices argued that fair use would serve as an effective counterweight to the increased copyright protections. This shift in judicial interpretations of fair use was heavily influenced by Judge Pierre N. Leval's 1990 article in the Harvard Law Review [3] that focused on the role of "transformativeness" in fair use. Judges now tend to apply Leval's two-step test, asking first if the use is transformative (i.e. used for a new purpose, context, audience, or insight) and second if the appropriate amount was used to satisfy the transformative use.

In addition to the two-step test, important factors in fair use decisions are custom and the practice of individual creative communities, especially when these are well-documented. In a 2004 article that appeared in the William \& Mary Law Review [4], University of Pittsburgh law professor Michael J. Madison examined past fair use decisions looking for commonalities. He found that judges tended to support the creative activities of legitimate communities that could 
articulate the values that motivated their cultural practices. It was this insight that lead to the development of best practices codes.

Aufderheide explained that she and Peter Jaszi began their work to create codes of best practices because, despite the liberal interpretations of fair use espoused by legal scholars, creators wanted more comfort in making their individual decisions. The Center for Social Media has facilitated the creation of fair use codes for a number of communities, including documentary filmmakers, film scholars, media literacy educators, users of dance-related materials, and creators of online video and OpenCourseWare. Documentary filmmakers were startled to discover, when they examined their practices, that there were a number of topics they shied away from making films about, for example anything to do with popular music and movies, public affairs, news, and parody. The filmmakers engaged in lengthy discussions about the practices that they themselves thought should fall under fair use. They identified four situations common in documentary filmmaking in which fair use should apply and documented them in a code of practice. Within weeks, documentary films were being shown at the Sundance Film Festival with clearances that would not have been possible without the code. Over the course of the next year, and because they had this code to guide them, insurers of errors and omissions in documentary films agreed (for the first time in two decades) to insure for fair use. Fair use claims are now being covered at no added cost.

Aufderheide stressed that these are codes of best practices, not guidelines. They are principles, not rules; limitations, not bans; and require reasoning in their application, not rote. She 
explained that fair use matters to librarians because it enables them to fulfill their mission of preserving knowledge and carrying it forward to the future. Libraries preserve culture; they preserve copyrighted artifacts. To remain relevant and to meet their users' needs, libraries must be able to digitize these artifacts. "Is the past going to become a black hole into which everything copyrighted in the twentieth century disappears until it emerges into the public domain?" asked Aufderheide.

In the two years that Aufderheide and Jaszi worked with librarians to develop the Code, they found that copyright was an open wound in the library world. Innovative projects would be started, then librarians would realize that too many permissions were needed and that obtaining them would take too much time, so the projects would be stopped. Projects that seemed important were not getting done; needs were not being met. This insecurity and hesitation meant that libraries' missions were deformed, for example when useful digital projects were avoided, digitized materials were hidden behind passwords, and the digitization of high-interest materials was passed over for more obscure projects that would be less likely to attract copyright complaints. In short, fair use was under-used and risk aversion was substituted for fair use analysis.

Butler explained that the Code of Best Practices in Fair Use for Academic and Research Libraries was created through deep deliberation by librarians themselves. Ninety librarians from sixty-four institutions engaged in nine four-hour discussions. A variety of institutions from across the country were represented, and participants were promised complete confidentiality so 
that they would not self-censor. Based on these deliberations, a consensus was reached around each of the eight principles documented in the Code, which was then reviewed by a diverse panel of five copyright experts.

The Code serves as a new input for the management of copyright risk in libraries. Relying on the Code does not eliminate the risk of being sued. In this way, using the Code is like using one's free speech rights: One can speak the truth and nonetheless be sued for libel and need to defend oneself in court, yet this risk should not stop one from speaking the truth. Butler also pointed out that the Code will not prevent libraries from receiving "cease and desist" letters from copyright holders. Such letters are inexpensive and easy to send, while litigation is expensive. A key point to keep in mind is that, when a library is not certain that a use is fair, the copyright holder is not sure either. If the copyright holder sues the library, it will cost them money, and they might lose the case. There are very few fair use cases in the courts each year, and of those that are heard, more are being decided in favor of fair use.

The Code can help librarians put legal risks into perspective and balance them with the need to carry out the library's mission and the importance of the activity in question. How the rights holder might be affected can be balanced with the importance of a project and the new research that will become possible if the project is completed. Librarians will be less likely to avoid activities that are genuinely useful to their users. Furthermore, the Code can create solidarity through community. As more librarians refer to the Code in moving forward with projects, fair use rights will become stronger for the library community as a whole. 
After this introduction to fair use and the history of the Code, Butler and Aufderheide proceeded to discuss each of the eight fair use principles in the document as well as taking a number of questions from attendees. Butler stressed that every principle in the code is qualified by a series of Limitations, which describe the outer limits of the principle, as well as Enhancements, which suggest ways for libraries to further strengthen their fair use case. These Limitations and Enhancements are very important to the successful application of fair use.

The first principle states, "It is fair use to make appropriately tailored course-related content available to enrolled students via digital networks." [5] The librarians who created the code felt strongly that activities such as creating online course reserves were legitimate in the support of teaching and that all libraries were engaging in these practices. Butler noted that librarians' shared understanding of the fair use of these current practices is in opposition to the 1976 "Classroom Guidelines" created by the Congressional Ad Hoc Committee on Copyright Law Revision. [6] These industry-written guidelines, which are not part of copyright legislation and thus are not legally binding, state that copies can be made for classroom use only if there was no time to request permission from the rights holder, that entire works cannot be made available, and that the same item cannot be used from term to term.

From the audience, Ellen Faran, Director of the MIT Press, brought up her concern that the code is silent about subsequent uses of course materials made available digitally by libraries. Publishers are worried that students can download entire works and then disseminate them. 
Butler replied that the quantity of a work used should depend on a professor's underlying rationale for using it. What makes a use fair is that a student in class is experiencing the work in the context of the course, which makes the use transformative. Access to material should be limited to students in the course, though the librarians who created the code did not come to a consensus on the best ways to achieve this. Butler noted that security is an arms race that no one can win; what is important is a library's good faith efforts to limit use to the appropriate people and to not make the material easy to copy. Publishers should realize, however, that many business models are better than free; for example, people will chose to pay a small amount to download a song from iTunes rather than download a free, lower-quality copy from a filesharing site. Publishers should not get hung up on the idea of perfect security, because this is the enemy of a viable business model.

Another audience member asked if libraries are liable for copyright violations committed by users who acquired copyrighted material from the library. Butler responded that the easy answer is "no" and referred attendees to his recent ARL Policy Notes blog post for a longer answer to the question. [7] Wilcoxson agreed that libraries cannot control what their users do with digital materials. He added that librarians should be careful when they post materials— such as materials in an online exhibit— to third-party platforms like Facebook or Flickr, for example. Third-party sites may have draconian terms of use, and librarians may be granting a license for downstream users to use library materials unfairly, even if the library's original use was fair. 
Butler segued to the second fair use principle in the Code, which refers to exhibits, both physical and virtual. After a librarian in the audience asked whether it was necessary to involve university counsel in decisions about which exhibit materials can be made available under fair use guidelines, the conversation among the panelists and attendees shifted to the role of university counsel. Wilcoxson from MIT stressed the importance of librarians' teaching their university counsel about the business of libraries and what libraries do. He believes it is best for librarians to reach out to counsel before they need an answer to a specific question, or when in crisis mode. He advised librarians in the room to give their counsels a copy of the Code and then approach them to discuss it further. Aufderheide echoed this point, suggesting that attendees present their counsel with a copy of the Code and tell them that ARL, an association of the finest research libraries in America, has defined best practices with regard to fair use, and that their library would like to conform to these best practices.

Courtney of the Harvard Law School Library discussed his experience working with Harvard's Office of the General Counsel to develop the Harvard Library Copyright and Fair Use Tool [8]. The Law School Library worked with General Counsel to find examples of fair use that they agreed on, for example showing movies in classes. They then moved on to discuss areas that were less clear, deepening their relationship as they did so. Courtney also helped develop a list of copyright "first responders," people whom librarians and others with copyright questions could call for advice. Wilcoxson offered the suggestion that if librarians want to appeal to counsel in their own language, they can point out that good faith reliance on fair use can reduce liability and potential damages, and following the Code is evidence of good faith. Butler added that the burden of proof in a fair use lawsuit is on the plaintiff; they have to prove that a library acted in 
bad faith, and if they cannot do that, they cannot collect damages. Furthermore, public institutions have state sovereign immunity that insulates them from paying damages for copyright infringement.

An audience member asked why no specific examples were given to illustrate each principle in the Code. Aufderheide responded that none of the codes provide specific examples, because such examples tend to create a "ceiling and a floor" problem-that is, what starts out as a floor, or platform on which to develop, becomes a ceiling, or limit of possibility. People tend to apply the fallacy of misplaced concreteness to individual examples. The goal of the code is not to define exactly what can and cannot be done under fair use, but to encourage librarians and others to own the reasoning in the code. Fair use is a free speech right, a First Amendment right. We have a situation in which librarians and other users of content have become disempowered; they are "begging permission in their minds." Instead, we need to become agents and learn to apply fair use principles in our work.

Butler returned to the principles of fair use and presented the third principle, which addresses digitization to preserve at-risk items. Section 108 of the Copyright Act authorizes selected preservation activities but does not adequately address the need to preemptively preserve at-risk materials, including materials stored in a format that is outdated but not yet obsolete (for example VHS tapes). The key to fair use in this situation is a library's inability to buy a copy of the item in a current format. 
The fourth principle in the Code concerns creating digital collections of archival and special collections materials. Butler stressed the transformative nature of the curating process with regard to these types of materials. Digital collections gather together materials around a specific theme in order to tell a story that no single item in the collection alone can tell. The transformative nature of this activity falls under fair use, even when specific items in the collection are protected by copyright. Butler offered the example of the personal archives of linguist Noam Chomsky, which were recently acquired by the MIT Libraries. Chomsky is known for maintaining files of newspaper clippings on a variety of topics. If the MIT Libraries were to digitize and make available some of those clippings within the context of a collection that illustrated Chomsky's life and work, that would be fair use.

The fifth principle addresses the reproduction of material for use by disabled students, faculty, staff, and other appropriate users. Butler noted that the 1996 Chafee Amendment, which added Section 121 to the Copyright Act, provides in part that "it is not an infringement of copyright for an authorized entity to reproduce or to distribute copies or phonorecords of a previously published, nondramatic literary work if such copies or phonorecords are reproduced or distributed in specialized formats exclusively for use by blind or other persons with disabilities." [9] Unfortunately, the Association of American Publishers has taken the position that educational institutions are not "authorized entities" under the Act, and the Authors Guild fears that recordings of copyrighted content read aloud will undermine the market for books on tape. In light of these restrictive interpretations of Section 121, libraries may reproduce material for disabled users under the protection of fair use, so long as fully accessible copies are not readily available from commercial sources. 
The Code's sixth principle states that it is fair use for a library to make publicly available through its institutional repository material that includes selections from copyrighted works-for example quotations, excerpts, or images-if the original use of the copyrighted material by the faculty member or student was itself a fair use. The seventh principle in the Code addresses the creation of digital databases to facilitate "non consumptive" research uses, including search. Google is an example: When we search Google, we are actually searching a copy of the Internet that resides on Google's servers. Non-consumptive uses, such as digitizing and indexing works for statistical meta-analysis and search, are highly transformative, and thus fall under the protection of fair use.

The eighth and final principle addresses creating and making available topically based collections of material from the World Wide Web. Butler noted that just because libraries cannot get permission to do so, does not mean they should not collect the Web. The Code states, "Such collections represent a unique contribution to knowledge and pose no significant risks for owners either of the sites in question or third-party material to which those sites refer. In the absence of such collections, important information is likely to be lost to scholarship." [10] As an example of such a collection, Butler mentioned Columbia University's Human Rights Web Archive. [11]

Butler concluded the presentation by stressing that "practice makes practice," that is, exercising fair use rights strengthens libraries' ability to use them. Fair use rights are "like a muscle;" you have to "use it or lose it." He mentioned that more information on fair use—including videos, 
presentations, teaching materials, and FAQ's-is available on the Web sites of the Association for Research Libraries [12] and the Center for Social Media. [13] For a deeper grounding on the topic, Butler recommended Aufderheide and Jaszi's book Reclaiming Fair Use: How to Put Balance Back in Copyright [14]. Hands-on and practical, the book offers a short history of the evolution of fair use, reviews the logic of key cases, and describes the methods by which codes of best practices are created.

More questions and discussion followed the presentation of the Code. Two themes that emerged in discussion were the notion of "appropriateness" and that fair use must be decided on a case-bycase basis. A use will be fair if it is transformative and if the amount used is appropriate in the given context. The notion of fair use allows for creativity in its application; there are no specific rules to determine if a use is fair; this requires the ability to make case-by-case decisions in the context of ambiguity.

An attendee asked whether librarians should avoid seeking permission to use copyrighted material, because if permission is denied and the librarian proceeds to use the material anyway, claiming fair use, this could show a lack of good faith. Butler stated that it is not the case that by asking permission, one waives fair use rights. He provided the example of hip hop musical group 2 Live Crew who sought permission from Acuff-Rose Music to sample a part of the Roy Orbison song "Oh, Pretty Woman.” After Acuff-Rose refused their request, 2 Live Crew went ahead and used a portion of the Orbison song in their parody song "Pretty Woman." The 
Supreme Court ruled in the landmark case Cambell v. Acuff-Rose Music that 2 Live Crew's use was fair.

Aufderheide added that Peter Jaszi believes that asking for permission can sometimes strengthen a fair use claim by revealing the obstacles involved in creating a new cultural expression. For example, documentary filmmakers are often denied permission to use copyrighted materials by the estates of persons profiled in their films, especially if the documentary treats the person critically. This is a censorship issue, not a market issue. An audience member asked if seeking permission before using copyrighted materials should be a best practice, given these examples. Butler replied that one of the benefits of the Code is that, in some contexts, projects that would have been stopped by the presumption of needing to seek permissions will go forward as librarians become comfortable relying first on fair use.

A related question involved the use of documentation, for example checklists that indicate the steps a library has taken to secure permissions or to document the process of deciding if a use is fair. Courtney responded that he used to be pro-documentation until he read the depositions in the Georgia State copyright case (Cambridge University Press et al. v. Patton et al.). Wilcoxson added that he is not a fan of checklists because library staff will either check the appropriate boxes to arrive at the "right" answer (allowing use of the work) or, after arriving at the "wrong" answer, will proceed to use the work anyway. The problem with checklists is that they make rote a process which is inherently fluid. That being said, the ability to articulate why a use is fair is important, and such statements can in and of themselves help prove fair use. Thus, documents 
that make people think about why they are using material can be helpful; checklists are not. Butler added that there was no consensus among the creators of the Code about whether or not professors should have to write down why they believe the use they are requesting is fair. What is important is that they can articulate a reason for the use; writing it down is less important. Aufderheide commented that when we ask faculty to think about their use of copyrighted materials, we are involved in a cultural training program. We are moving fair use into a new place in their minds where they can use it. Once we understand fair use, it is no longer a monster in the closet, but a leveler of the playing field.

\section{References}

[1] Prudence Adler, Patricia Aufderheide, Brandon Butler, Peter Jaszi, American University (Washington, D.C.) Center for Social Media, Washington College of Law, and Andrew W. Mellon Foundation, Code of best practices in fair use for academic and research libraries, Washington, D.C.: Association of Research Libraries, 2012. Online. Available: http://www.arl.org/bm doc/code-of-best-practices-fair-use.pdf (accessed March 29, 2012).

[2] Center for Social Media, "Codes," http://www.centerforsocialmedia.org/fair-use/related-

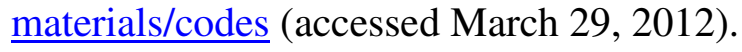


[3] Pierre N. Leval, "Toward a fair use standard," Harvard Law Review 103, no. 5 (March 1990): 1105-1136.

[4] Michael J. Madison, "A pattern-oriented approach to fair use," William \& Mary Law Review 45, no. 4 (2004): 1525-1690.

[5] Prudence Adler, et al., Code of best practices, 14.

[6] See Copyright Clearance Center, "Using Content: Photocopies: Classroom Guidelines," http://www.copyright.com/Services/copyrightoncampus/content/index_class.html (Accessed March 30, 2012) and University of Louisville, "Classroom Guidelines (1976)," http://louisville.edu/copyright/resources/classroom-guidelines-1976.html (Accessed March 30, 2012).

[7] Brandon Butler, "Should libraries fret over mischievous users?" ARL Policy Notes (blog), http://policynotes.arl.org/post/19399576582/should-libraries-fret-over-mischievous-users (Accessed April 2, 2012). 
[8] Harvard University Library Office for Scholarly Communication, "Harvard Library copyright and fair use tool," http://osc.hul.harvard.edu/liblab/proj/harvard-library-copyright-and-fair-usetool (Accessed April 2, 2012).

[9] Association of Research Libraries, "Briefing: Accessibility, the Chafee Amendment, and Fair Use," http://www.arl.org/pp/ppcopyright/codefairuse/accessibility.shtml (Accessed April 5, 2012).

[10] Prudence Adler, et al., Code of best practices, 26.

[11] Columbia University Libraries, Center for Human Rights Documentation \& Research, "Human Rights Web Archive," http://library.columbia.edu/indiv/humanrights/hrwa.html (Accessed April 5, 2012).

[12] Association of Research Libraries, "Code of Best Practices in Fair Use for Academic and Research Libraries," http://www.arl.org/pp/ppcopyright/codefairuse/index.shtml (Accessed April 5, 2012).

[13] Center for Social Media, "Fair Use," http://www.centerforsocialmedia.org/fair-use (Accessed April 5, 2012). 
[14] Patricia Aufderheide and Peter Jaszi, Reclaiming Fair Use: How to Put Balance Back in Copyright, Chicago: University of Chicago Press, 2011.

\title{
Contact info:
}

\author{
Andrée J. Rathemacher \\ Head, Acquisitions \\ University Libraries, University of Rhode Island \\ 15 Lippitt Road \\ Kingston, RI 02881-2011 \\ Phone: (401) 874-5096 \\ Fax: (401) 874-4588 \\ E-mail: andree@uri.edu \\ http://www.uri.edu/library/
}

